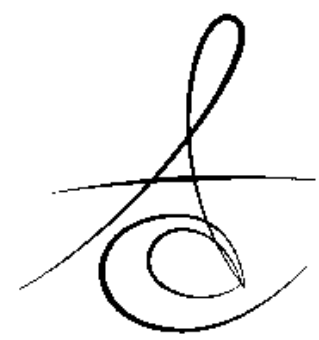

Makale Kodu/Article code: 3154

Makale Gönderilme tarihi: 24.11 .2016

Kabul Tarihi: 12.01.2017

\section{BEYAZ ÖNLÜK KORKUSU GERÇEK Mİ?}

IS FEAR OF WHITE COAT REAL?

\author{
Dr. Gizem İNAN
}

Dr. Ahmet COSKUN

\section{öz}

Amaç: Çocuk doktorlarının ve çocuk diş hekimlerinin hasta bakarken önlüklerini çıkarmaları konusu yıllardır süren bir tartışmadır. Çocukla kurulan iletişimde anksiyete ile ilgili faktörlerle birlikte, hekimlerin yaklaşımı ve görünüşü de etkili olmaktadır. Çocuklarda beyaz önlük korkusu olduğu sonucunu bulgulayan çalışmalar olduğu gibi; aksini iddia eden çalışmalar da mevcuttur. Bu çalışmada amaç, yaş ve dental tecrübe ayrımı yapılarak 512 yaş çocuklarının diş hekimi kıyafet ve yardımcı ekipmanları hakkındaki tercihlerini ve bu tercihlerde etkili olan faktörleri araştırmaktır.

Gereç ve Yöntem: Çalışma Gazi Üniversitesi Diş Hekimliği Fakültesi Pedodonti Anabilim Dalı'na 2016 Mayıs-Temmuz ayları arasında başvuran 5-12 yaş araIığındaki dental tecrübesi olan/olmayan 462 çocukta gerçekleştirildi. Çocuklara beyaz önlüklü, renkli alt-üst takımlı, pediatrik önlüklü, günlük kıyafetli ve resmi kıyafetli erkek ve kız manken fotoğrafları gösterilerek tercihleri soruldu. Bone ve maskelerin farklı renk ve desenlerdeki örnekleri gösterilerek öncelikle bunları tercih edip etmedikleri, ardından hangisini tercih ettikleri soruldu. Hastaya çeşitli renklerdeki eldivenler sunularak hastanın tercihi kayıt edildi.

Bulgular: Dental tecrübesi olan ve olmayan çocuklar arasında tercihler açısından istatistiksel olarak anlamlı fark bulunmadı. Çocukların en çok beyaz önlük tercih ettiği; cinsiyete göre tercih açısından anlamlı fark bulunmadığı; çocukların yaşı büyüdükçe tercihlerin da- ha fazla beyaz önlük yönünde olduğu görüldü. Hem kız hem erkek çocuklar beyaz maskeyi desenli maskeye tercih etti. Erkeklerin beyaz eldiven, beyaz bone; kız- ların pembe eldiven, renkli bone tercih ettiği görüldü.

Sonuç: Tercihlerin dental tecrübeden ziyade, yaşa bağlı olarak beyaz önlük yönünde değişim gösterdiği görülmüştür. $\mathrm{Bu}$ da, çocukların erken yaşlarda diş hekimine gelmese bile, izlediği çizgi filmlerden, kitap ve dergilerden diş hekimi kıyafeti ve beyaz önlük konusunda fikir sahibi olduklarını düşündürmektedir.

Anahtar Kelimeler: Çocuk diş hekimliği, dental ekipman, hasta tercihi

\section{ABSTRACT}

Aim: It has been a long standing controversy among pediatricians whether to remove white coats when attending to patients. Outlook and attitude of pediatric specialists inevitably impact their communication with children. There are studies claiming that children fear the white coat as well as those which report otherwise. The aim of this study is to evaluate preferences of children aged between 5-12 for outfit and auxiliary equipment used by dentists and the examine the factors which affect these preferences.

Materials and Methods: The study was conducted on 462 children aged between 5-12 years who were admitted to Department of Pedodontics at Gazi University between May-July 2016. The patients were asked to report their preferences on pictures of male and female models wearing white coats, colored coats, pediatric coats, casual and formal clothes. They were shown caps, masks, and gloves of different colors and designs and asked to tell which ones they prefer.

Results: No significant difference was found between children that have dental experience and those that do not. It was found that children prefered white coat to other attire, that no significant gender-specific difference exists in coat preference, and that children increasingly prefered white coat as they grow older. Further, both boys and girls prefered white mask, and boys prefered white gloves and cap while girls chose pink gloves and colored caps.

Conclusion: Our findings indicate that the preferences depend on age rather than dental experience. This suggests that even if a child does not visit dentists at early ages, he/she might gain experience through books, TV, etc. about dental outfit.

Keywords: Pediatric dentistry, dental equipment, patient preference.

*Ege Üniversitesi, Diş Hekimliği Fakültesi, Ağız Diş ve Çene Cerrahisi, İzmir

* 24-28 Eylül 2016 tarihinde Kuşadası'nda düzenlenen 23. Türk Pedodonti Derneği Kongresi'nde poster olarak sunulmuştur.

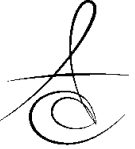




\section{GİRİŞ}

Çocuklarda diş hekimi korkusu oldukça sık rastlanan; etiyolojisi tam olarak anlaşılamayan fakat dental tedaviler sırasında önemli bir engel oluşturan bir durumdur. ${ }^{1,2}$

Diş hekimi korkusunun; her yaşta görülmekle birlikte daha sık olarak çocukluk ve ergenlik döneminde ortaya çıktığı bildirilmektedir. ${ }^{3}$ Her ne kadar psikolojinin gelişimine bağlı diş hekimi korkusunun 6-7 yaşlarında azalması beklenilse de; bu korku daha ilerideki yaşlarda da devam edebilmektedir. Hatta bu korku yaşanılan tecrübeye bağı olarak da gelişebilmektedir. ${ }^{4}$

Korkuyu etkileyen faktörler değişkenlik gösterirken, diş hekiminin uygun kıyafetleri çocuk ve diş hekiminin başarılı bir iletişim kurmasına katkıda bulunabilir. ${ }^{1,2}$ Çocuk doktorlarının ve çocuk diş hekimlerinin hasta bakarken önlüklerini çıkarmaları gerektiği konusu da yıllardır süre gelen bir tartışmadır.

$\mathrm{Bu}$ konu üzerinde çalışan Barrett ve Booth ${ }^{1}$, geleneksel beyaz kıyafetinin olumsuz yönlerini ilk bildiren kişiler olmuştur. Çocukların resmi olarak giyinmiş doktorları yetkili olarak gördüklerini; ancak samimi bulmadıklarını gözlemlemişlerdir.

Çocukların hoşlanacağı objeleri ihtiva eden; çocuk dostu olarak isimlendirilen hekim kıyafet ve ekipmanlarının daha kabul edilebilir olduğu bildirilmiştir. ${ }^{5}$

Çocuklarda beyaz önlük korkusu olduğu sonucunu bulgulayan çalışmalar ${ }^{6,7}$ olduğu gibi; aksini iddia eden araştırmalar ${ }^{1,8-10}$ da mevcuttur. Beyaz önlük korkusunun olabileceğini savunan çalışmalarda bu korkunun özellikle anksiyete sahibi çocuklarda bulunduğu, anksiyetesi olan çocukların anksiyetesi olmayan çocuklara göre daha çok renkli önlük, daha az beyaz önlük tercih ettikleri bulunmuştur. ${ }^{6,7}$

Konu ile ilgili literatür araştırması yapıldığında yaş ve dental tecrübe ayrımının birlikte gerçekleştirildiği bir çalışmaya rastlanılmamıştır.

$\mathrm{Bu}$ çalışmadaki amaç, yaş ve dental tecrübe ayrımı yapılan 5-12 yaş aralığındaki çocukların diş hekimi kıyafet ve yardımcı ekipmanları hakkındaki tercihlerini araştırmak ve bu tercihler üzerinde hangi faktörün daha etkili olduğunu tespit etmektir.

\section{GEREÇ ve YÖNTEM}

Çalışma için Gazi Üniversitesi Etik Kurulu Başkanlığı'ndan 139286 sayılı etik kurul onayı alındı. Çalışma Gazi Üniversitesi Diş Hekimliği Fakültesi
Pedodonti Anabilim Dalı́na 2016 Mayıs-Temmuz ayları arasında başvuran 5-12 yaş aralığındaki daha önce dental tecrübesi olan veya olmayan ve anket çalışmasına katılmayı kabul eden tüm çocuklar üzerinde gerçekleştirildi. Çalışmaya 251 kIz 211 erkek olmak üzere toplam 462 çocuk katıldı. Çalışmaya başlamadan önce çocuklara ve velilerine çalışma hakkında bilgi verilerek onamları istendi. Velisi ve kendisi çalışmaya katılmayı kabul eden çocuklara beyaz önlüklü (Resim 1a), renkli alt-üst takımlı (Resim $1 b$ ), pediatrik önlüklü (Resim 1c), günlük kıyafetli (Resim 1d) ve resmi kıyafetli (Resim 1e) erkek ve kız manken fotoğrafları gösterildi. Çocuklara tüm fotoğraflara baktıktan sonra diş hekimlerinin hangi kıyafeti giymesini tercih ettikleri soruldu. Sonrasında yardımcı ekipman olan bone (Resim 2a-b-c) ve maskelerin (Resim 3a-b) farklı renk ve desenlerdeki örnekleri gösterildi. Öncelikle bunları tercih edip etmedikleri, daha sonra da doktorlarının kullanımı için hangisini tercih ettikleri soruldu. Son olarak hastalara beyaz, mor, pembe ve mavi renklerdeki eldiven fotoğrafları (Resim 4a,b,c,d), sunularak hastanın tercihi kayıt edildi. Kayıt edilen tüm sonuçlar çalışmanın istatistiksel analizinin yapılması için listelendi. Elde edilen veriler SPSS 22 (SPSS Inc, Chicago, IL, ABD) paket programı aracılığı ile analiz edildi. Değişkenler arası değerlendirmeler ki-kare analizi ile gerçekleştirildi.

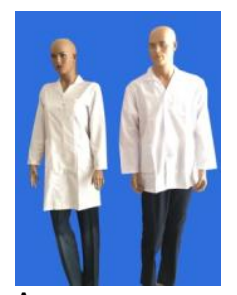

A
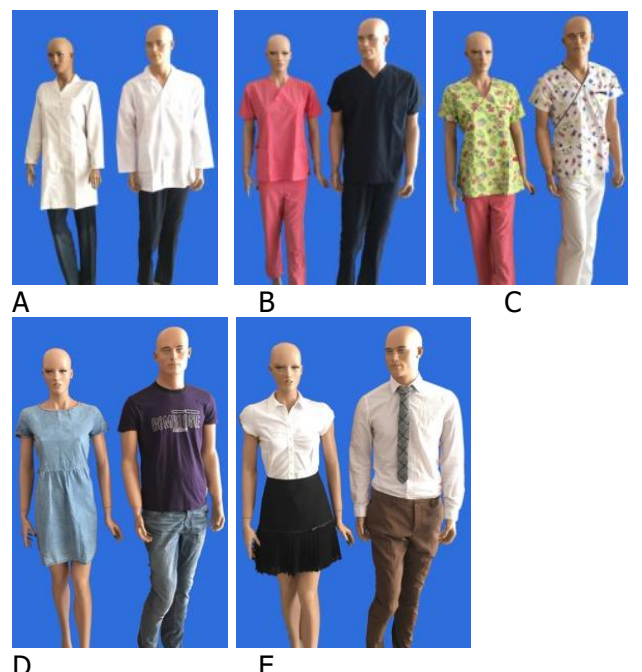

B

C

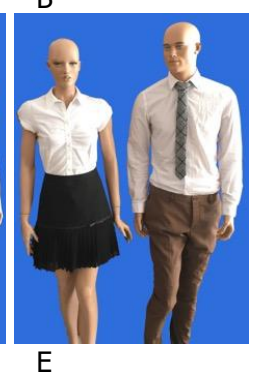

Resim 1a: Beyaz önlük, b: Renkli alt-üst önlük c: Pediatrik önlük, d: Günlük kıyafet e: Resmi kıyafet

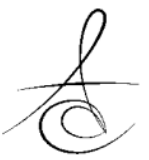




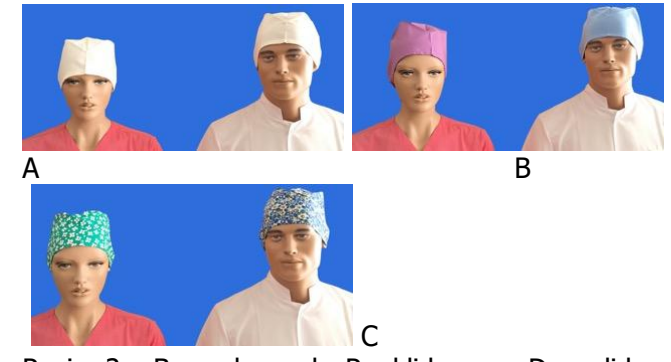

Resim 2a: Beyaz bone, b: Renkli bone,c: Desenli bone

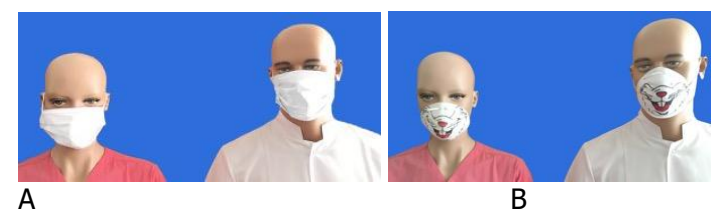

Resim 3a: Beyaz maske, b: Desenli maske

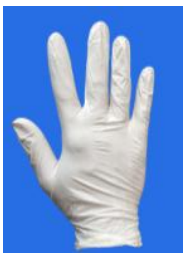

A

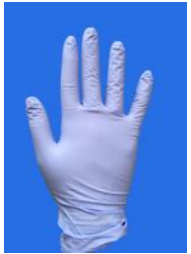

B

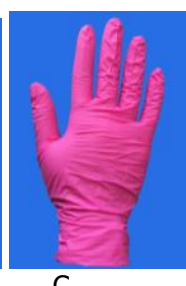

C

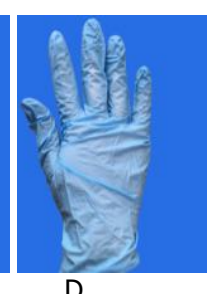

D
Resim 4a: Beyaz eldiven, b:Mor eldiven, c: Pembe eldiven, d: Mavi eldiven

\section{BULGULAR}

Erkeklerin daha yüksek oranda beyaz renk tercih ettiği görülmekle birlikte $(\% 47,9)$; cinsiyetler arasında kıyafet tercihi açısından istatistiksel olarak anlamlı bir farklıık görülmedi ( $p>0,05)$ (Tablo 1).

Maske isteme açısından cinsiyetler arasında anlamlı bir farklılık görülmedi ( $p>0,05)$. Her iki cinsiyette de doktorunun maske takmasını isteyen çocukların oranının yüksek olduğu gözlendi. Maske seçiminde ise erkekler daha yüksek oranda $(\% 65,9)$ beyaz maskeyi tercih ederken; kızlarda bu oranın \% 57,4 olduğu bulundu. Bu sonuç istatistiksel olarak anlamlı bulunmadı $(p>0,05)$.

$\mathrm{K} \mathrm{z}$ çocukların istatistiksel olarak anlamlı derecede yüksek oranda doktorlarının bone takmasını istemediği tespit edildi $(p<0,05)$. Erkek çocuklar daha çok beyaz bone tercih ederken, kız çocukların daha yüksek oranda renkli bone istediği bulundu. Erkeklerin eldiven tercihi beyaz eldiven olurken, kızlarda bu tercihin pembe eldiven yönünde olduğu görüldü $(p<0,05)$. Kıyafet, maske, eldiven ve bone olarak hepsini beyaz tercih eden çocuklarda cinsiyetler arası istatistiksel olarak anlamlı bir fark görülmedi $(p>0,05)$.
Tablo 1. Çalışmaya katılan çocukların tercihlerinin cinsiyete göre dağılımı

\begin{tabular}{|c|c|c|c|c|c|c|c|c|c|}
\hline & \multicolumn{6}{|c|}{ Cinsiyet } & & \\
\hline & & \multicolumn{2}{|c|}{ Kadın } & \multicolumn{2}{|c|}{ Erkek } & \multicolumn{2}{|c|}{ Toplam } & & \\
\hline & & $\mathrm{n}$ & $\%$ & $\mathrm{n}$ & $\%$ & $\mathrm{n}$ & $\%$ & Ki-Kare & $\mathrm{p}$ \\
\hline \multirow{6}{*}{ 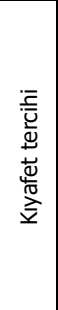 } & $\begin{array}{l}\text { Beyaz } \\
\text { Önlük }\end{array}$ & 80 & 31,9 & 101 & 47,9 & 181 & 39,2 & \multirow{6}{*}{29,1} & \multirow{6}{*}{$0,0001^{*}$} \\
\hline & $\begin{array}{l}\text { Renkli } \\
\text { Önlük }\end{array}$ & 59 & 23,5 & 44 & 20,9 & 103 & 22,3 & & \\
\hline & $\begin{array}{l}\text { Desenli } \\
\text { Önlük }\end{array}$ & 49 & 19,5 & 11 & 5,2 & 60 & 13,0 & & \\
\hline & $\begin{array}{l}\text { Günlük } \\
\text { Kıyafet }\end{array}$ & 23 & 9,2 & 29 & 13,7 & 52 & 11,3 & & \\
\hline & $\begin{array}{l}\text { Resmi } \\
\text { Kiyafet }\end{array}$ & 40 & 15,9 & 26 & 12,3 & 66 & 14,3 & & \\
\hline & Toplam & 251 & 100,0 & 211 & 100,0 & 462 & 100,0 & & \\
\hline \multirow{3}{*}{ 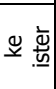 } & Evet & 178 & 70,9 & 163 & 77,3 & 341 & 73,8 & \multirow{3}{*}{2,3} & \multirow{3}{*}{0,123} \\
\hline & \begin{tabular}{|l|} 
Hayır \\
\end{tabular} & 73 & 29,1 & 48 & 22,7 & 121 & 26,2 & & \\
\hline & Toplam & 251 & 100,0 & 211 & 100,0 & 462 & 100,0 & & \\
\hline \multirow{3}{*}{ 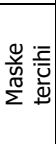 } & $\begin{array}{l}\text { BEYAZ } \\
\text { MASKE } \\
\end{array}$ & 144 & 57,4 & 139 & 65,9 & 283 & 61,3 & \multirow{3}{*}{3,4} & \multirow{3}{*}{0,062} \\
\hline & $\begin{array}{l}\text { DESENLİ } \\
\text { MASKE }\end{array}$ & 107 & 42,6 & 72 & 34,1 & 179 & 38,7 & & \\
\hline & Toplam & 251 & 100,0 & 211 & 100,0 & 462 & 100,0 & & \\
\hline \multirow{3}{*}{ 䍃 } & Evet & 193 & 76,9 & 144 & 68,2 & 337 & 72,9 & \multirow{3}{*}{4,3} & \multirow{3}{*}{$0,037 *$} \\
\hline & Hayır & 58 & 23,1 & 67 & 31,8 & 125 & 27,1 & & \\
\hline & Toplam & 251 & 100,0 & 211 & 100,0 & 462 & 100,0 & & \\
\hline \multirow{4}{*}{ 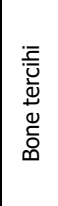 } & $\begin{array}{l}\text { Beyaz } \\
\text { Bone }\end{array}$ & 83 & 33,1 & 121 & 57,3 & 204 & 44,2 & \multirow{4}{*}{30,8} & \multirow{4}{*}{$0,0001^{*}$} \\
\hline & $\begin{array}{l}\text { Renkli } \\
\text { Bone }\end{array}$ & 105 & 41,8 & 67 & 31,8 & 172 & 37,2 & & \\
\hline & $\begin{array}{l}\text { Desenli } \\
\text { Bone }\end{array}$ & 63 & 25,1 & 23 & 10,9 & 86 & 18,6 & & \\
\hline & Toplam & 251 & 100,0 & 211 & 100,0 & 462 & 100,0 & & \\
\hline \multirow{5}{*}{ 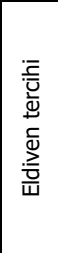 } & $\begin{array}{l}\text { Beyaz } \\
\text { Eldiven }\end{array}$ & 87 & 34,7 & 106 & 50,2 & 193 & 41,8 & \multirow{5}{*}{101,8} & \multirow{5}{*}{$0,0001^{*}$} \\
\hline & $\begin{array}{l}\text { Mor } \\
\text { Eldiven }\end{array}$ & 27 & 10,8 & 16 & 7,6 & 43 & 9,3 & & \\
\hline & $\begin{array}{l}\text { Pembe } \\
\text { Eldiven }\end{array}$ & 127 & 50,6 & 28 & 13,3 & 155 & 33,5 & & \\
\hline & $\begin{array}{l}\text { Mavi } \\
\text { Eldiven }\end{array}$ & 10 & 4,0 & 61 & 28,9 & 71 & 15,4 & & \\
\hline & Toplam & 251 & 100,0 & 211 & 100,0 & 462 & 100,0 & & \\
\hline \multirow{3}{*}{ 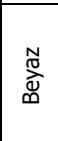 } & \begin{tabular}{|l|} 
Hepsi \\
Beyaz \\
\end{tabular} & 41 & 16,3 & 45 & 21,3 & 86 & 18,6 & \multirow{3}{*}{1,8} & \multirow{3}{*}{0,171} \\
\hline & $\begin{array}{l}\text { En Az Birisi } \\
\text { Beyaz Deği }\end{array}$ & 210 & 83,7 & 166 & 78,7 & 376 & 81,4 & & \\
\hline & Toplam & 251 & 100,0 & 211 & 100,0 & 462 & 100,0 & & \\
\hline
\end{tabular}

n: örnek sayısı N: örnek yüzdesi $*$ İstatistiksel olarak anlamlı fark var

Çalışmaya katılan çocuklardan dental tecrübesi olan ve olmayan çocuklar arasında maske isteyip istememe oranları dışında tercihler açısından anlamlı bir fark bulunmadı (Tablo 2).

Çalışmaya katılan çocukların kıyafet tercihlerinin yaşa göre dağılımı Tablo $3^{\prime}$ te; maske isteme ve maske tercihi oranları Tablo 4 ve 5 'te; bone isteme ve bone tercihi oranları Tablo 6 ve 7'de; eldiven tercihleri ise Tablo 8'de gösterildi. Özellikle 7 yaşından büyük çocuklarda yaş ilerledikçe bone, maske isteme oranlarının arttığı görüldü.

Çocukların yaş ilerledikçe gerek kıyafette gerekse yardımcı ekipmanda beyaz olanı tercih etme oranının arttığı tespit edildi (Tablo 9). 
Atatürk Üniv. Diş Hek. Fak. Derg.

İNAN, ULUSU,

J Dent Fac Atatürk Uni

COŞKUN

Cilt:28, Sayı:2, Yıl: 2018, Sayfa, 182,187

Tablo 2. Çalışmaya katılan çocukların tercihlerinin dental tecrübeye göre dağılımı

\begin{tabular}{|c|c|c|c|c|c|c|c|c|c|}
\hline & \multicolumn{6}{|c|}{ Cinsiyet } & \multirow[b]{3}{*}{ Ki-Kare } & \multirow[b]{3}{*}{$\mathrm{P}$} \\
\hline & & \multicolumn{2}{|c|}{ Kadın } & \multicolumn{2}{|c|}{ Erkek } & \multicolumn{2}{|c|}{ Toplam } & & \\
\hline & & $\mathrm{N}$ & $\%$ & $\mathrm{~N}$ & $\%$ & $\mathrm{~N}$ & $\%$ & & \\
\hline \multirow{6}{*}{ 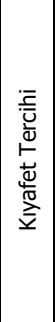 } & $\begin{array}{l}\text { Beyaz } \\
\text { Önlük }\end{array}$ & 115 & 40,8 & 66 & 36,7 & 181 & 39,2 & \multirow{6}{*}{1,7} & \multirow{6}{*}{0,775} \\
\hline & $\begin{array}{l}\text { Renkli } \\
\text { Önlük }\end{array}$ & 60 & 21,3 & 43 & 23,9 & 103 & 22,3 & & \\
\hline & $\begin{array}{l}\text { Desenli } \\
\text { Önlük }\end{array}$ & 39 & 13,8 & 21 & 11,7 & 60 & 13,0 & & \\
\hline & $\begin{array}{l}\text { Günlük } \\
\text { Kıyafet }\end{array}$ & 30 & 10,6 & 22 & 12,2 & 52 & 11,3 & & \\
\hline & $\begin{array}{l}\text { Resmi } \\
\text { KIyafet }\end{array}$ & 38 & 13,5 & 28 & 15,6 & 66 & 14,3 & & \\
\hline & Toplam & 282 & 100,0 & 180 & 100,0 & 462 & 100,0 & & \\
\hline \multirow{3}{*}{ 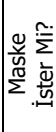 } & Evet & 221 & 78,4 & 120 & 66,7 & 341 & 73,8 & \multirow{3}{*}{7,7} & \multirow{3}{*}{$0,005^{*}$} \\
\hline & Hayır & 61 & 21,6 & 60 & 33,3 & 121 & 26,2 & & \\
\hline & Toplam & 282 & 100,0 & 180 & 100,0 & 462 & 100,0 & & \\
\hline \multirow{3}{*}{ 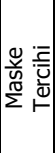 } & $\begin{array}{l}\text { Beyaz } \\
\text { Maske }\end{array}$ & 179 & 63,5 & 104 & 57,8 & 283 & 61,3 & \multirow{3}{*}{1,5} & \multirow{3}{*}{0,221} \\
\hline & $\begin{array}{l}\text { Desenli } \\
\text { Maske }\end{array}$ & 103 & 36,5 & 76 & 42,2 & 179 & 38,7 & & \\
\hline & Toplam & 282 & 100,0 & 180 & 100,0 & 462 & 100,0 & & \\
\hline \multirow{3}{*}{ 商. } & Evet & 208 & 73,8 & 129 & 71,7 & 337 & 72,9 & \multirow{3}{*}{0,244} & \multirow{3}{*}{0,622} \\
\hline & Hayır & 74 & 26,2 & 51 & 28,3 & 125 & 27,1 & & \\
\hline & Toplam & 282 & 100,0 & 180 & 100,0 & 462 & 100,0 & & \\
\hline \multirow{4}{*}{ 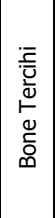 } & $\begin{array}{l}\text { Beyaz } \\
\text { Bone }\end{array}$ & 127 & 45,0 & 77 & 42,8 & 204 & 44,2 & \multirow{4}{*}{4,2} & \multirow{4}{*}{0,124} \\
\hline & $\begin{array}{l}\text { Renkli } \\
\text { Bone }\end{array}$ & 96 & 34,0 & 76 & 42,2 & 172 & 37,2 & & \\
\hline & $\begin{array}{l}\text { Desenli } \\
\text { Bone }\end{array}$ & 59 & 20,9 & 27 & 15,0 & 86 & 18,6 & & \\
\hline & Toplam & 282 & 100,0 & 180 & 100,0 & 462 & 100,0 & & \\
\hline \multirow{5}{*}{ 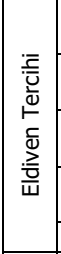 } & $\begin{array}{l}\text { Beyaz } \\
\text { Eldiven }\end{array}$ & 130 & 46,1 & 63 & 35,0 & 193 & 41,8 & \multirow{5}{*}{6,1} & \multirow{5}{*}{0,106} \\
\hline & $\begin{array}{l}\text { Mor } \\
\text { Eldiven }\end{array}$ & 26 & 9,2 & 17 & 9,4 & 43 & 9,3 & & \\
\hline & $\begin{array}{l}\text { Pembe } \\
\text { Eldiven }\end{array}$ & 88 & 31,2 & 67 & 37,2 & 155 & 33,5 & & \\
\hline & $\begin{array}{l}\text { Mavi } \\
\text { Eldiven } \\
\end{array}$ & 38 & 13,5 & 33 & 18,3 & 71 & 15,4 & & \\
\hline & Toplam & 282 & 100,0 & 180 & 100,0 & 462 & 100,0 & & \\
\hline \multirow{3}{*}{ 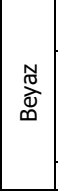 } & $\begin{array}{l}\text { Hepsi } \\
\text { Beyaz }\end{array}$ & 55 & 19,5 & 31 & 17,2 & 86 & 18,6 & \multirow{3}{*}{0,37} & \multirow{3}{*}{0,536} \\
\hline & $\begin{array}{l}\text { En Az } \\
\text { Birisi } \\
\text { Beyaz } \\
\text { Değil }\end{array}$ & 227 & 80,5 & 149 & 82,8 & 376 & 81,4 & & \\
\hline & Toplam & 282 & 100,0 & 180 & 100,0 & 462 & 100,0 & & \\
\hline
\end{tabular}

Tablo 4. Çalışmaya katılan çocukların maske isteme oranının yaşa göre dağılımı

\begin{tabular}{|l|r|r|r|r|r|r|r|r|}
\hline \multirow{3}{*}{ Yaş } & \multicolumn{7}{|c|}{ Maske ister mi? } & \multirow{2}{*}{} \\
\cline { 2 - 7 } & \multicolumn{2}{|c|}{ Evet } & \multicolumn{1}{|c|}{ Hayır } & \multicolumn{1}{|c|}{ Toplam } & & \\
\cline { 2 - 7 } & $\mathrm{n}$ & $\mathrm{N}$ & $\mathrm{n}$ & \multicolumn{1}{|c|}{$\mathrm{N}$} & \multicolumn{1}{c|}{$\mathrm{n}$} & $\mathrm{N}$ & Ki-Kare & $\mathrm{p}$ \\
\hline 5 & 55 & 63,2 & 32 & 36,8 & 87 & 100,0 & & \\
\hline 6 & 72 & 71,3 & 29 & 28,7 & 101 & 100,0 & & \\
\hline 7 & 47 & 68,1 & 22 & 31,9 & 69 & 100,0 & & \\
\hline 8 & 50 & 70,4 & 21 & 29,6 & 71 & 100,0 & \multirow{3}{*}{20,2} & \multirow{2}{*}{$0,005^{*}$} \\
\hline 9 & 56 & 86,2 & 9 & 13,8 & 65 & 100,0 & \\
\hline 10 & 35 & 85,4 & 6 & 14,6 & 41 & 100,0 & & \\
\hline 11 & 18 & 94,7 & 1 & 5,3 & 19 & 100,0 & & \\
\hline 12 & 8 & 88,9 & 1 & 11,1 & 9 & 100,0 & & \\
\hline Toplam & 341 & 73,8 & 121 & 26,2 & 462 & 100,0 & & \\
\hline
\end{tabular}

Tablo 5. Çalışmaya katılan çocukların maske tercihlerinin yaşa göre dağılımı

\begin{tabular}{|c|c|c|c|c|c|c|c|c|}
\hline \multirow[t]{3}{*}{ Yaş } & \multicolumn{6}{|c|}{ Maske tercihi } & \multirow[b]{3}{*}{$\begin{array}{l}\text { Ki- } \\
\text { Kare }\end{array}$} & \multirow[b]{3}{*}{$\mathrm{p}$} \\
\hline & \multicolumn{2}{|c|}{ BEYAZ MASKE } & \multicolumn{2}{|c|}{ DESENLİ MASKE } & \multicolumn{2}{|c|}{ Toplam } & & \\
\hline & $\mathrm{n}$ & $\mathrm{N}$ & $\mathrm{n}$ & $\mathrm{N}$ & $\mathrm{n}$ & $N$ & & \\
\hline 5 & 39 & 44,8 & 48 & 55,2 & 87 & 100,0 & 31,5 & $0,0001^{*}$ \\
\hline 6 & 50 & 49,5 & 51 & 50,5 & 101 & 100,0 & & \\
\hline 7 & 52 & 75,4 & 17 & 24,6 & 69 & 100,0 & & \\
\hline 8 & 48 & 67,6 & 23 & 32,4 & 71 & 100,0 & & \\
\hline 9 & 42 & 64,6 & 23 & 35,4 & 65 & 100,0 & & \\
\hline 10 & 29 & 70,7 & 12 & 29,3 & 41 & 100,0 & & \\
\hline 11 & 14 & 73,7 & 5 & 26,3 & 19 & 100,0 & & \\
\hline 12 & 9 & 100,0 & 0 & 0,0 & 9 & 100,0 & & \\
\hline Topl. & 283 & 61,3 & 179 & 38,7 & 462 & 100,0 & & \\
\hline
\end{tabular}

Tablo 6. Çalışmaya katılan çocukların bone isteme oranlarının yaşa göre dağılımı

\begin{tabular}{|c|c|c|c|c|c|c|c|c|}
\hline \multirow{3}{*}{ Yaş } & \multicolumn{6}{|c|}{ Bone ister mi? } & & \\
\hline & \multicolumn{2}{|c|}{ Evet } & \multicolumn{2}{|c|}{ Hayır } & \multicolumn{2}{|c|}{ Toplam } & \multirow[b]{2}{*}{ Ki-Kare } & \multirow[b]{2}{*}{$p$} \\
\hline & $\mathrm{n}$ & $\mathrm{N}$ & $\mathrm{n}$ & $\mathrm{N}$ & $\mathrm{n}$ & $\mathrm{N}$ & & \\
\hline 5 & 70 & 80,5 & 17 & 19,5 & 87 & 100,0 & \multirow{9}{*}{4,7} & \multirow{9}{*}{0,695} \\
\hline 6 & 74 & 73,3 & 27 & 26,7 & 101 & 100,0 & & \\
\hline 7 & 47 & 68,1 & 22 & 31,9 & 69 & 100,0 & & \\
\hline 8 & 51 & 71,8 & 20 & 28,2 & 71 & 100,0 & & \\
\hline 9 & 45 & 69,2 & 20 & 30,8 & 65 & 100,0 & & \\
\hline 10 & 28 & 68,3 & 13 & 31,7 & 41 & 100,0 & & \\
\hline 11 & 15 & 78,9 & 4 & 21,1 & 19 & 100,0 & & \\
\hline 12 & 7 & 77,8 & 2 & 22,2 & 9 & 100,0 & & \\
\hline Toplam & 337 & 72,9 & 125 & 27,1 & 462 & 100,0 & & \\
\hline
\end{tabular}

Tablo 3. Çalışmaya katılan çocukların kıyafet tercihlerinin yaşa göre dağılımı

\begin{tabular}{|c|c|c|c|c|c|c|c|c|c|c|c|c|c|c|}
\hline \multirow{3}{*}{ Yaş } & \multicolumn{12}{|c|}{ Kıyafet tercihi } & & \\
\hline & \multicolumn{2}{|c|}{ BEYAZ ÖNLÜK } & \multicolumn{2}{|c|}{ RENKLİ ÖNLÜK } & \multicolumn{2}{|c|}{ DESENLİ ÖNLÜK } & \multicolumn{2}{|c|}{ GÜNLÜK KIYAFET } & \multicolumn{2}{|c|}{ RESMİ KIYAFET } & \multicolumn{2}{|c|}{ Toplam } & \multirow[b]{2}{*}{ Ki-Kare } & \multirow[b]{2}{*}{$\mathrm{p}$} \\
\hline & $\mathrm{n}$ & $\mathrm{N}$ & $\mathrm{n}$ & $\mathrm{N}$ & $\mathrm{n}$ & $\mathrm{N}$ & $\mathrm{n}$ & $\mathrm{N}$ & $\mathrm{n}$ & $\mathrm{N}$ & $\mathrm{n}$ & $\mathrm{N}$ & & \\
\hline 5 & 22 & 25,3 & 25 & 28,7 & 13 & 14,9 & 12 & 13,8 & 15 & 17,2 & 87 & 100,0 & \multirow{9}{*}{42,3} & \multirow{9}{*}{$0,036 *$} \\
\hline 6 & 29 & 28,7 & 19 & 18,8 & 14 & 13,9 & 16 & 15,8 & 23 & 22,8 & 101 & 100,0 & & \\
\hline 7 & 35 & 50,7 & 11 & 15,9 & 7 & 10,1 & 7 & 10,1 & 9 & 13,0 & 69 & 100,0 & & \\
\hline 8 & 33 & 46,5 & 14 & 19,7 & 10 & 14,1 & 7 & 9,9 & 7 & 9,9 & 71 & 100,0 & & \\
\hline 9 & 28 & 43,1 & 18 & 27,7 & 6 & 9,2 & 6 & 9,2 & 7 & 10,8 & 65 & 100,0 & & \\
\hline 10 & 19 & 46,3 & 8 & 19,5 & 7 & 17,1 & 3 & 7,3 & 4 & 9,8 & 41 & 100,0 & & \\
\hline 11 & 7 & 36,8 & 7 & 36,8 & 3 & 15,8 & 1 & 5,3 & 1 & 5,3 & 19 & 100,0 & & \\
\hline 12 & 8 & 88,9 & 1 & 11,1 & 0 & 0,0 & 0 & 0,0 & 0 & 0,0 & 9 & 100,0 & & \\
\hline Toplam & 181 & 39,2 & 103 & 22,3 & 60 & 13,0 & 52 & 11,3 & 66 & 14,3 & 462 & 100,0 & & \\
\hline
\end{tabular}


Tablo 7. Çalışmaya katılan çocukların bone tercihlerinin yaşa göre dağılımı

\begin{tabular}{|c|c|c|c|c|c|c|c|c|c|c|}
\hline \multirow{3}{*}{ Yaş } & \multicolumn{8}{|c|}{ Bone tercihi } & & \\
\hline & \multicolumn{2}{|c|}{$\begin{array}{l}\text { BEYAZ } \\
\text { BONE }\end{array}$} & \multicolumn{2}{|c|}{$\begin{array}{l}\text { RENKLI } \\
\text { BONE }\end{array}$} & \multicolumn{2}{|c|}{$\begin{array}{c}\text { DESENLİ } \\
\text { BONE }\end{array}$} & \multicolumn{2}{|c|}{ Toplam } & & \\
\hline & $\mathrm{n}$ & $\mathrm{N}$ & $\mathrm{n}$ & $\mathrm{N}$ & $n$ & $\mathrm{~N}$ & $\mathrm{n}$ & $\mathrm{N}$ & $\begin{array}{l}\text { Ki- } \\
\text { Kare }\end{array}$ & $\mathrm{p}$ \\
\hline 5 & 23 & 26,4 & 46 & 52,9 & 18 & 20,7 & 87 & 100,0 & & \\
\hline 6 & 40 & 39,6 & 36 & 35,6 & 25 & 24,8 & 101 & 100,0 & & \\
\hline 7 & 38 & 55,1 & 20 & 29,0 & 11 & 15,9 & 69 & 100,0 & & \\
\hline 8 & 31 & 43,7 & 26 & 36,6 & 14 & 19,7 & 71 & 100,0 & & \\
\hline 9 & 33 & 50,8 & 21 & 32,3 & 11 & 16,9 & 65 & 100,0 & 30,3 & $0,007 *$ \\
\hline 10 & 20 & 48,8 & 17 & 41,5 & 4 & 9,8 & 41 & 100,0 & & \\
\hline 11 & 11 & 57,9 & 5 & 26,3 & 3 & 15,8 & 19 & 100,0 & & \\
\hline 12 & 8 & 88,9 & 1 & 11,1 & 0 & 0,0 & 9 & 100,0 & & \\
\hline Toplam & 204 & 44,2 & 172 & 37,2 & 86 & 18,6 & 462 & 100,0 & & \\
\hline
\end{tabular}

Tablo 8. Çalışmaya katılan çocukların eldiven tercihlerinin yaşa göre dağıımı

\begin{tabular}{|c|c|c|c|c|c|c|c|c|c|c|c|c|}
\hline \multirow[t]{3}{*}{ Yass } & \multicolumn{10}{|c|}{ Edventerchi } & & \\
\hline & \multicolumn{2}{|c|}{ BEYAZ } & \multicolumn{2}{|c|}{ MOR } & \multicolumn{2}{|c|}{ PEMBE } & \multicolumn{2}{|c|}{ MAV் } & \multicolumn{2}{|c|}{ Toplam } & & \\
\hline & $n$ & $\mathrm{~N}$ & $n$ & $\mathrm{~N}$ & $\mathrm{n}$ & $\mathrm{N}$ & $n$ & $\mathrm{~N}$ & $n$ & $\mathrm{~N}$ & $\begin{array}{c}\mathrm{K}- \\
\mathrm{Kae}\end{array}$ & $p$ \\
\hline 5 & 18 & 20,7 & 6 & 6,9 & 44 & 50,6 & 19 & 21,8 & 87 & 100,0 & 73,2 & $0,0001^{*}$ \\
\hline 6 & 28 & 27,7 & 10 & 9,9 & 45 & 44,6 & 18 & 17,8 & 101 & 100,0 & & \\
\hline 7 & 46 & 66,7 & 6 & 8,7 & 14 & 20,3 & 3 & 4,3 & 69 & 100,0 & & \\
\hline 8 & 27 & 38,0 & 11 & 15,5 & 21 & 29,6 & 12 & 16,9 & 71 & 100,0 & & \\
\hline 9 & 29 & 44,6 & 7 & 10,8 & 17 & 26,2 & 12 & 18,5 & 65 & 100,0 & & \\
\hline 10 & 24 & 58,5 & 3 & 7,3 & 10 & 24,4 & 4 & 9,8 & 41 & 100,0 & & \\
\hline 11 & 13 & 68,4 & 0 & 0,0 & 3 & 15,8 & 3 & 15,8 & 19 & 100,0 & & \\
\hline 12 & 8 & 88,9 & 0 & 0,0 & 1 & 11,1 & 0 & 0,0 & 9 & 100,0 & & \\
\hline Topl. & 193 & 41,8 & 43 & 9,3 & 155 & 33,5 & 71 & 15,4 & 462 & 100,0 & & \\
\hline
\end{tabular}

Tablo 9. Tüm tercihleri beyaz olan çocukların yaşa göre dağııımı

\begin{tabular}{|c|c|c|c|c|c|c|c|c|}
\hline \multirow[t]{3}{*}{ Yaş } & \multicolumn{6}{|c|}{ Beyaz } & & \\
\hline & \multicolumn{2}{|c|}{$\begin{array}{l}\text { Hepsi } \\
\text { Beyaz }\end{array}$} & \multicolumn{2}{|c|}{$\begin{array}{l}\text { En az birisi } \\
\text { Beyaz Değil }\end{array}$} & \multicolumn{2}{|c|}{ Toplam } & & \\
\hline & $n$ & $\mathrm{~N}$ & $n$ & $\mathrm{~N}$ & $n$ & $\mathrm{~N}$ & $\begin{array}{l}\text { Ki- } \\
\text { Kare }\end{array}$ & $p$ \\
\hline 5 & 5 & 5,7 & 82 & 94,3 & 87 & 100,0 & 49,7 & $0,0001^{*}$ \\
\hline 6 & 9 & 8,9 & 92 & 91,1 & 101 & 100,0 & & \\
\hline 7 & 26 & 37,7 & 43 & 62,3 & 69 & 100,0 & & \\
\hline 8 & 11 & 15,5 & 60 & 84,5 & 71 & 100,0 & & \\
\hline 9 & 13 & 20,0 & 52 & 80,0 & 65 & 100,0 & & \\
\hline 10 & 12 & 29,3 & 29 & 70,7 & 41 & 100,0 & & \\
\hline 11 & 4 & 21,1 & 15 & 78,9 & 19 & 100,0 & & \\
\hline 12 & 6 & 66,7 & 3 & 33,3 & 9 & 100,0 & & \\
\hline Topl. & 86 & 18,6 & 376 & 81,4 & 462 & 100,0 & & \\
\hline
\end{tabular}

\section{TARTIŞMA}

Çocuk tarafından diş hekimi hakkında verilen ilk yargının hekimin görünüşüne göre olduğu ve çoğunlukla çocukların ilk randevuda hekimin her sözünü, her hareketini, her ifadesini zihinlerine kaydettikleri vurgulanmıştır. ${ }^{11,12}$ Bugün dental vizit sırasında çocuk dostu yaklaşımın çocukların diş tedavisini kabullenmesi ve işbirliği yapması yönünden faydalı olduğu bildirilmiştir. ${ }^{13}$

Çocuk diş hekimi çocuğun daha rahat kabul edebileceği olumlu düzenlemeler yapmak için hangi kıyafet türünün daha tercih edilebilir olacağına önem vermelidir. Psikologlar ve sosyologlar tarafından da bu görünüşün önemi ve bunun ilk izlenimlerle kişiler arası ilişkiler üzerindeki etkisini vurguladıkları bildirilmiştir. ${ }^{1}$

Çocuklarda gerek beyaz önlük korkusunun araştırıldığı; gerekse çocukların ne tür kıyafetleri daha çok tercih ettiğinin sorgulandığı birçok çalışma yapılmış ve farklı sonuçlar bulunmuştur. ${ }^{1,6-10}$

Barret ve Booth'ın yaptığı bir çalışmada genel olarak bilindiği gibi çocukların geleneksel beyaz önlüğe negatif yanıt verdiği ancak resmi kıyafetleri daha kolay tolere ettikleri ileri sürülmüştür. ${ }^{14}$ Aksine Kuşçu ve arkadaşları ${ }^{15}$ yaptıkları bir çalışmada çalışmaya katılan çocukların \%45.6' sının beyaz önlük tercih ettiğini belirtmişlerdir. Yapılan bir başka çalışmada hem çocukların ve hem de velilerinin ilk tercihinin beyaz önlük olduğu, ikinci tercihlerinin ise çocuk dostu pediatrik önlükler olduğu belirtilmiştir. ${ }^{1}$ Kuşçu ve diğerleri $^{4}$ yaptıkları bir başka çalışmada kültürel ve sosyoekonomik olarak farklı çevrede yetişen çocukların anksiyetelerinin ve tercihlerinin buna göre değişebileceğini belirtmişlerdir.

Sonuç olarak çocuklarda beyaz önlük korkusu olduğu sonucunu bulgulayan çalışmalar olduğu gibi; aksini iddia eden araştırmalar da mevcuttur. Çalışmaların bir çoğunda ${ }^{1-5}$ dental tecrübe ayrımı yapılmamıştır. Bu çalışmada çocukların hekim kıyafet ve ekipman tercihleri incelenirken; bunun cinsiyet ve yaşla olan bağlantısının yanı sıra, dental tecrübeyle olan ilişkisi de değerlendirilmiştir. Çalışmanın sonuçlarına göre cinsiyetler arasında kıyafet tercihlerinde bir farklılık bulunmamıştır. Her iki grupta da beyaz önlük tercihinin birinci sırada olduğu görülmüştür.

Hem kız hem de erkek çocukların 'Diş hekiminizin maske/bone takmasını ister misiniz?" sorusuna yüksek oranda evet dediği belirlenmiştir. Kıyafet, maske, bone ve eldiven tercihlerinin tamamını beyazdan yana kullanan çocuklarda da cinsiyetler arasında anlamlı fark bulunmamıştır. Çocukların 'Diş hekiminizin maske/bone takmasını ister misiniz?" soru- larına yüksek oranda evet demesi çocukların hekimin hijyeni konusuna önem verdiğini düşündürmüştür.

Dental tecrübesi olan ve olmayan çocuklar arasında ise kıyafet, maske, bone, eldiven tercihleri açısından anlamlı bir fark bulunmamıştır. Bununla beraber çocukların beyaz önlük, beyaz maske, beyaz bone, beyaz eldiven seçme oranlarının özellikle 7 yaşından sonra artış gösterdiği ve yaş büyüdükçe bu oranın arttığı belirlenmiştir. 
Çocuğun kişisel ve psikolojik gelişimine bağlı olarak diş hekimi korkusunun 6-7 yaşlarında azalmasının beklendiği bilinmektedir. ${ }^{4}$ Çalışmanın sonuçlarına göre de özellikle 7 yaşından sonra çocukların daha profesyonel görünümü tercih etmesi dikkat çekmiştir.

Çalışmanın tüm sonuçları değerlendirildiğinde çocukların, diş hekimlerinin kıyafetleri ve yardımcı ekipmanları tercihleri üzerinde cinsiyetin önemli olmadığı; dental tecrübeden ziyade yaşın daha etkili olduğu sonucuna varılmışırır.

Yüksek oranda beyaz kıyafet ve yardımcı ekipman seçiminin daha önceki çalışmalarda ${ }^{8,9}$ da bahsedildiği gibi profesyonel görünümle ilişkilendirilebileceği düşünülmüştür.

Daha önceki birçok çalışmanın ${ }^{8,15,16}$ sonuçlarında da bulgulandığı gibi bu çalışmadan da beyaz önlük kaygısı gibi bir yaygın inanışın doğruluğunu kanıtlayan sonuçlar çıkmamıştır.

\section{SONUÇ}

Tercihlerin dental tecrübeden ziyade, yaşa bağlı olarak beyaz önlük yönünde değişim gösterdiği görülmüştür. Bu da, çocukların erken yaşlarda diş hekimine gelmese bile, izlediği çizgi filmlerden, kitap ve dergilerden diş hekimi kıyafeti ve beyaz önlük konusunda fikir sahibi olduklarını düşündürmektedir.

Çıkar Çatışması: Yazarlar bu çalışmayla ilgili herhangi bir çıkar çatışmalarının bulunmadığını bildirmişlerdir.

Gizem İnan, ORCID ID: 0000-0002-6895-5458

Tezer Ulusu, ORCID ID: 0000-0001-7724-0617

Ahmet Co,kun, ORCID ID: 0000-0002-1375-5037

\section{KAYNAKLAR}

1. Kamavaram Ellore VP, Mohammed M, Taranath M, Ramagoni NK, Kumar V, Gunjalli G. Children and Parent's Attitude and Preferences of Dentist's Attire in Pediatric Dental Practice. Int J Clin Pediatr Dent 2015; 8: 102-7.

2. Mistry D, Tahmassebi JF. Children's and parents' attitudes towards dentists' attire. Eur Archs Paediatr Dent 2009;10:237-41.

3. Bayrak Ş, Şen Tunç E, Eğilmez T, Tüloğlu N. Ebeveyn dental kaygısı ve sosyodemografik faktörlerin çocukların dental kaygısı üzerine etkileri. Atatürk Üniv Diş Hek Fak Derg 2010;20:181-8.

4. Kuş̧̧u OO, Akyüz S. Children's preferences concerning the physical appearance of dental injectors. J Dent Child 2006;73:116-21.

5. Vagnoli L, Caprilli S, Robiglio A, Messeri A. Clown doctors as a treatment for preoperative anxiety in children: a randomized, postpective study. Pediatr 2005; 116: 563-567.

6. Nirmala SV, Veluru S, Nuvvula S, Chilamakuri S. Preferences of Dentist's Attire by Anxious and Nonanxious Indian Children. J Dent Child 2015; 82: 97-101.

7. Asokan A, Kambalimath HV, Patil RU, Maran S, Bharath KP. A survey of the dentist attire and gender preferences in dentally anxious children. J Indian Soc Pedod Prev Dent 2016; 34: 30-5.

8. Zeren AE, Öktem ZB, Can İ, Bezgin T, Özalp N. What to wear when practicing on pediatric dental patients?. J of Pediatr Dent 2016; 4: 37-41.

9. AlSarheeda M. Children's Perception of Their Dentists. Eur J Dent 2011; 5: 186-190.

10. Panda A, Garg I, Bhobe AP. Children's perspective on the dentist's attire. Int J Paediatr Dent 2014; 24: 98-103.

11. Kleinknecht RA, Klepac RK, Alexander LD. Origins and characteristics of fear of dentistry. J Am Dent Assoc 1973; 86: 842-6.

12. Brosky ME, Keefer OA, Hodges JS, Pesun IJ, Cook G. Patient perceptions of professionalism in dentistry. J Dent Educ 2003; 67: 909-15.

13. American Academy on Pediatric Dentistry Clinical Affairs Committee-Behavior Management Subcommittee; American Academy on Pediatric Dentistry Council on Clinical Affairs. Guideline on behavior guidance for the pediatric dental patient. Pediatr Dent 2008-2009;30 7 Suppl: 125-33.

14. Barrett T.G, Booth I.W. Sartorialeloquence: does it exist in the paediatrician patient relationship? BrMed J 1994; 309:1710-2.

15. Kuscu OO, Çağlar E, Kayabasoglu N, Sandallı N. Short communication: Preferences of dentis's attire in a group of Istanbul school related with dental anxiety. Eur Arch Paediatr Dent 2009;10, 38-41.

16. McCarthy JJ, McCarthy MC, Eilert RE. Children's and parents' visual perception of physicians. Clin Pediatr (Phila) 1999; 38: 145-52
Yazışma Adresi
Gizem İnan,
Gazi Üniversitesi, Diş Hekimliği Fakültesi, Pedodonti Anabilim Dalı, Ankara, Türkiye
Tel: +09 03122034090
Fax: +09 03122239226
E-mail: gizeminan @hotmail.com 